\title{
Fiscal Policy Spillovers through Trade Openness
}

Georgios Karras

University of Illinois at Chicago, Chicago, Illinois, USA

\begin{abstract}
This paper studies whether trade openness reduces the domestic fiscal multiplier, but increases the impacts of foreign fiscal shocks, i.e., the spillover effect, as suggested by theory. Using annual data from the period of 1970 to 2011, for 179 developed and developing economies, we show that domestic fiscal shocks are less potent in more open economies, while foreign (rest of the world) fiscal shocks are more potent in more open economies.
\end{abstract}

JEL Classifications: E32, E62

Key words: Fiscal Policy, Fiscal Multiplier, Fiscal Spillover Effects, Trade Openness

* Corresponding Author: Georgios Karras; Department of Economics, University of Illinois at Chicago, IL 606077121, USA; Tel: +312 9962321, Fax: +312 9963344, E-mail: gkarras@uic.edu.

Acknowledgements: I wish to thank an anonymous referee of this journal for helpful comments and suggestions. All errors and omissions remain mine. 


\section{Introduction}

In the wake of the recent global financial crisis, macroeconomic stabilization in various countries has increasingly relied on fiscal policies. As a result, the economic impacts have once again become the subject of extensive theoretical and empirical research.

However, virtually all of the recent studies have ignored the possible spillover effects of fiscal policy. The literature has almost exclusively focused on estimating the effects of a country's fiscal policies on that country, but ignored the effects of these policies on other countries. The exception is the recent study by Auerbach and Gorodnichenko (2013) which estimates fiscal spillover effects for a sample of OECD economies, finding them to be not only economically and statistically significant, but also stronger during recessions.

The present paper contributes to the literature on fiscal spillovers in two ways. First, it estimates these effects for a much larger sample of 179 economies since $1970{ }^{3}$ Second, it focuses on the sensitivity of the spillover effects to the economies' trade openness, rather than the phase of the business cycle.

Theoretically, trade openness is recognized as one of the prime determinants of the magnitude of fiscal multipliers. Indeed, greater openness to international trade is generally predicted to reduce the effectiveness of domestic fiscal policy. ${ }^{4}$ This is obviously true in the standard Keynesian or Mundell-Fleming models in which government spending has maximum potency when the economy is relatively closed and its effects are largely contained in the domestic economy. On the other hand, if the economy is wide open, a large portion of a fiscal expansion will leak out on imported goods, reducing the overall effect on domestic aggregate demand. ${ }^{5}$ Precisely the

\footnotetext{
${ }^{1}$ Only a partial list of this literature, already very large but still growing rapidly, is possible. Theoretical contributions include Christiano, Eichenbaum, and Rebelo (2011), Eggertsson (2010), Fève, Matheron, and Sahuc (2013), and Woodford (2011). For empirical contributions, see Auerbach and Gorodnichenko's (2012), Barro and Redlick (2011), Cogan, Cwik, Taylor, and Wieland (2010), Hall (2009), and Mountford and Uhlig (2009). Ramey (2011) provides an excellent survey and guide.

${ }^{2}$ It is worth mentioning two other, slightly older but valuable exceptions. The theoretical contribution of Bénassy-Quéré (2006) focuses on the importance of monetary policy for the determination of fiscal spillovers in a monetary union; while the empirical study of Beetsma, Giuliodori, and Klaassen (2006) estimates cross-border transmission of fiscal shocks within the European Union.

${ }^{3}$ For comparison, Auerbach and Gorodnichenko's (2013) sample includes only OECD economies since 1984 (or 1990 , for some of the newer OECD member countries), while Beetsma, Giuliodori, and Klaassen's (2006) only EU countries, generally over $1965 \sim 2004$.

${ }^{4}$ See for example the recent IMF study by Spilimbergo, Symansky, and Schindler (2009).

${ }^{5}$ For the original Mundell-Fleming mechanisms, Fleming (1962) and Mundell (1968). Frenkel and Razin (1987) present a more recent presentation of the Mundell-Fleming Equation, while Obstfeld (2001) reconciles Mundell-Fleming with the more modern intertemporal,
} 
opposite properties are supposed to govern the effects of foreign fiscal shocks where a more open economy is more exposed to the changes in foreign government spending because more of their effect is imported. Overall, the more open the economy, the lower the predicted value of the domestic fiscal multiplier and the higher the predicted value of the spillover effect.

The importance of trade openness for the domestic effects of domestic fiscal shocks has been investigated empirically, most recently by Ilzetzki, Mendoza, and Vegh (2013), who find that fiscal expansions are more effective in closed economies than they are in open economies. The literature, however, has not examined whether fiscal spillover effects also depend on trade openness. As mentioned above, exploring the possible link between openness and fiscal spillovers is one of the key contributions of the present paper.

The paper analyzes annual data from the period of 1970 to 2011 for a sample of 179 developed and developing economies. The empirical findings show that the output effects of domestic fiscal shocks are much larger in less open economies, while the spillover effects of foreign fiscal shocks are much larger in more open economies. These differences are sizable and robust to various estimation techniques.

The rest of the paper is organized as follows. Section II discusses the sources of the data and defines the variables to be used in the estimation. Section III outlines the estimation methodology, derives the main empirical results, and implements a number of robustness checks. Section IV concludes.

\section{The Data}

All data are obtained from the UN National Accounts and the data set consists of a panel of the 179 economies for which annual data exist for each of the years 1970 2011. For country $i$ and time $t$, domestic output, $y_{i, t}$, is measured by real Gross Domestic Product (GDP), while domestic government purchases, $g_{i, t}$, is measured by real general government final consumption expenditure. Both series are expressed in the US dollars and at the constant 2005 prices. The Appendices provides a list of the 
179 economies. $^{6}$ As the Appendix clearly points out, the sample of countries is quite diverse, including economies which are at various stages of development, and which have had very different fiscal policies and output growth experiences.

Next, we construct our measures of world real GDP, $y_{t}^{w}=\sum_{j=1}^{179} y_{j, t}$, and world real government purchases, $g_{t}^{w}=\sum_{j=1}^{179} g_{j, t}$, essentially assuming that the world consists of these 179 economies.

Figure 1 plots both world variables and shows that they tend to move roughly together. For a more careful look, however, Figure 2 plots the world government size, defined as the ratio of the two variables, $g_{t}^{w} / y_{t}^{w}$, measuring world government consumption as a fraction of world GDP. Figure 2 shows that, while world government size has been indeed relatively smooth over time, a gentle downward trend is discernible: its value has declined from about $20 \%$ in 1970 to about $17 \%$ in 2011 .

Then, for country $i$ and time $t$, we define foreign output, $y_{i, t}^{f}$, and foreign government consumption, $y_{i, t}$, as the rest of the world values for $y_{i, t}$ and $g_{i, t}$, respectively.

Thus, $y_{i, t}^{f}=\sum_{j \neq i} y_{j, t}=y_{t}^{w}-y_{i, t}$ and $g_{i, t}^{f}=\sum_{j \neq i} g_{j, t}=g_{t}^{w}-g_{i, t}$.

Finally, we retrieve data on exports, $x_{i, t}$, and imports, $m_{i, t}$, in order to construct the standard trade openness variable, open $_{i, t}=\frac{x_{i, t}+m_{i, t}}{y_{i, t}}$, measuring total trade for country $i$ at time $t$ as a fraction of its GDP.

As already noted, country selection has been dictated by data availability only.

${ }^{7}$ The maximum value of $20.5 \%$ was achieved in 1982 , while the minimum of $16.8 \%$ in 2007

${ }^{8}$ Another variable of interest that can be constructed using our data is economic size, $S_{i, 0}$ measured by the fraction of global GDP produced by economy $i$ at time $t: S_{i, t}=y_{i, t} / y_{t}^{w}$. We note that, as expected, economic size and trade openness are negatively correlated, with correlation coefficient of -0.17 . 


\section{Empirical Evidence}

\section{A. The benchmark dynamic model}

We start with a simple dynamic specification that relates domestic output growth to foreign (rest of the world) output growth, and changes in domestic and foreign government consumption:

$$
\begin{aligned}
\frac{y_{i, t}-y_{i, t-1}}{y_{i, t-1}} & =\sum_{j=1}^{J} \alpha_{j} \frac{y_{i, t-j}-y_{i, t-j-1}}{y_{i, t-j-1}}+\sum_{j=1}^{J} \alpha_{j}^{f} \frac{y_{i, t-j}^{f}-y_{i, t-j-1}^{f}}{y_{i, t-j-1}^{f}} \\
& +\sum_{j=0}^{J} \beta_{j} \frac{g_{i, t-j}-g_{i, t-j-1}}{y_{i, t-j-1}}+\sum_{j=1}^{J} \beta_{j}^{f} \frac{g_{i, t-j}^{f}-g_{i, t-j-1}^{f}}{y_{i, t-j-1}^{f}}+u_{i, t}
\end{aligned}
$$

where, in addition to the previously used notation, $J$ is the number of lags, and the $\alpha^{\prime}$ s, $\alpha^{f}$ 's, $\beta$ 's, and $\beta^{f}$ 's, are parameters to be estimated. The $\alpha$ 's are autoregressive parameters that allow for persistence in the real growth rate; the $\alpha^{f}$ 's capture the effects of foreign output growth on domestic output; and the domestic output effects of domestic and foreign changes in government consumption are captured by the $\beta$ 's, and $\beta^{f}$ 's, respectively. The domestic long-run fiscal multiplier is given by $\sum_{j=0}^{J} \beta_{j} /\left(1-\sum_{j=1}^{J} \alpha_{j}\right)$, while the magnitude of the spillover effect is $\sum_{j=1}^{J} \beta_{j}^{f} /\left(1-\sum_{j=1}^{J} \alpha_{j}\right)$

Table 1 reports the long-run domestic multipliers and spillover effects estimated using Equation (1) for the full sample of 179 countries, for $J=4$. $^{9}$ We begin with the full sample not because we believe that the equation applies the same way to all of these economies, but in order to establish a first set of results comparable to the previous

${ }^{9}$ Different lag lengths were also tried, but results are robust and are not reported to preserve space. 
studies. The top row of Table 1 shows that the domestic multiplier ranges from 1.14 to 1.21 , depending on the method of estimation. ${ }^{10}$ The estimated standard errors suggest that the multipliers are highly statistically significantly different from zero, but only marginally statistically significantly greater than one. ${ }^{11}$ The bottom row of Table 1 shows that the point estimates of the long-run spillover effects are negative. However, they are very small in magnitude and statistically insignificant from zero.

It is worth noting that the estimated long-run values do not capture the full dynamic effects of a change in government spending, and this happens to be especially the case for the effects of foreign fiscal shocks. To illustrate, Appendix $\mathrm{C}$ reports the dynamic responses of domestic output to changes in domestic and foreign government consumption implied by Equation (1) for the full sample of 179 countries. It can be readily seen that focusing exclusively on the long-run values can result in overlooking substantial short-run effects, and this turns out to be particularly true for the foreign fiscal shocks. As Appendix C shows, while the domestic output effects of foreign government spending in the full sample are virtually zero in the long-run, they are estimated to be large and positive in the short run.

In a nutshell, the full sample results suggest that the output effects of domestic fiscal shocks are large, positive, and permanent whereas the spillover effects of foreign fiscal shocks are large, positive, and transitory.

So far, we have assumed that the equation can be applied in the same way to all 179 economies. In other words, we have imposed the constraint that the parameters are equal across the sample, regardless of country characteristics that could affect these parameters. The next subsection asks what happens to our empirical results when this constraint is relaxed.

\section{B. The role of trade openness}

As discussed earlier, greater openness of the domestic economy to international trade is predicted to weaken the ability of domestic fiscal policy to affect domestic output, but increase the effects of foreign fiscal policy on domestic output (the spillover effect). Put differently, the domestic fiscal multiplier is expected to be larger in less open

\footnotetext{
${ }^{10}$ As in all subsequent Tables, the first column (OLS) ignores country-specific effects, while the second and third columns Equation them as Fixed Effects (FE), and Random Effects (RE), respectively.

${ }^{11}$ Numerically, these estimates are therefore closer to those of Barro and Redlick's (2011) than Hall's (2009).
} 
economies, while the spillover effect is expected to be larger in more open economies.

To test these theoretical predictions using Equation (1), we now split the full sample in smaller subsets, each with different trade openness properties. Specifically, we first rank the 179 economies in terms of increasing average openness, $\overline{\text { open }} .^{12}$ In the full sample, the median value of $\overline{\text { open }}$ equals $71.97 \%$; while the 25 - and 75 -percentiles are $46.19 \%$ and $103.17 \%$, respectively. To construct two data subsets that are sufficiently different in terms of openness, we remove the middle half of the economies, and use the top and bottom quarters of the full data set (45 economies each) to build two distinct sub-samples: (i) the least open data set, consisting of all economies with average openness lower than $46.19 \%$; and (ii) the most open data set, consisting of all economies with average openness greater than $103.17 \%$. Appendix B lists the countries in each of the two subsets, together with each country's average openness statistic.

We now estimate Equation (1) separately for the least open and most open subsets, thereby relaxing the constraint that the parameters of the equation are independent of trade openness. Table 2 presents the estimated long-run domestic multipliers and spillover effects for both data sets with three estimation methods.

Beginning with the least open country estimates in Panel A of Table 2, we note that both domestic multipliers and spillover effects are estimated to be positive and sizable, though only the domestic multipliers are statistically significant. Moving on to Panel $\mathrm{B}$ of the most open country results, domestic multipliers and spillover effects are again positive and sizable, though now both are statistically significant.

Even more relevant for our present purposes is a comparison of domestic multipliers and spillover effects between the two subsets, and our findings appear to be fully consistent with the theoretical predictions. First, the estimated domestic multiplier ranges from 1.51 to 1.73 for the least open subset, but it is only about 0.60 for the most open economies. As predicted by the theory, domestic fiscal shocks are found to be less potent in more open economies.

Additionally, the estimated long-run effect of foreign fiscal shocks on domestic output is about 1.0 and statistically insignificant for the least open subset, but it ranges between 4.0 and 4.5 and is highly statistically significant for the most open economies. Government spending have greater effects on more open economies.

The Impulse Response Functions of domestic output implied by separate estimation

${ }^{12}$ This equals each country's trade openness averaged over 1970 2011: $\overline{\text { open }}_{i}=\frac{1}{42} \sum_{t=1970}^{2011}$ open $_{i, t}$. 
of Equation (1) for the two subsets of countries are reported in Figures 3 and 4. These clearly show the short-run and long-run output effects to be positive following increases in either domestic or foreign government spending.

Turning to a comparison between the two subsets of countries, Figure 3 shows that the output responses to domestic shocks are substantially higher for the least open economies; while Figure 4 shows how the output response to foreign shocks accumulates over time to a much larger effect for the most open economies.

Summing up the findings, the empirical results have been shown to be consistent with the theoretical predictions. The output effects of domestic fiscal shocks appear to be much larger in less open economies, while the spillover effects of foreign fiscal shocks are shown to be much larger in more open economies. These differences are sizable and robust to various estimation techniques.

\section{Additional robustness extensions}

Our measure of government purchases, like that of most of the related empirical literature, is less likely to be exogenous than Hall's (2009) or Barro and Redlick's (2011) variable which relies on military expenditure. Therefore, it is worth considering how our results might change if we exclude the contemporaneous domestic fiscal term from the right-hand side of Equation (1). To do this, we modify Equation (1) to:

$$
\begin{aligned}
\frac{y_{i, t}-y_{i, t-1}}{y_{i, t-1}}= & \sum_{j=1}^{J} \alpha_{j} \frac{y_{i, t-j}-y_{i, t-j-1}}{y_{i, t-j-1}}+\sum_{j=1}^{J} \alpha_{j}^{f} \frac{y_{i, t-j}^{f}-y_{i, t-j-1}^{f}}{y_{i, t-j-1}^{f}} \\
& +\sum_{j=1}^{J} \beta_{j} \frac{g_{i, t-j}-g_{i, t-j-1}}{y_{i, t-j-1}}+\sum_{j=1}^{J} \beta_{j}^{f} \frac{g_{i, t-j}^{f}-g_{i, t-j-1}^{f}}{y_{i, t-j-1}^{f}}+u_{i, t}
\end{aligned}
$$

where notation is as before, and the main change of consequence is that the domestic long-run fiscal multiplier is now given by $\sum_{j=1}^{J} \beta_{j} /\left(1-\sum_{j=1}^{J} \alpha_{j}\right)$. The estimated Impulse Response Functions for both subsets of countries are reported in Figure 5 for the domestic fiscal shocks, and in Figure 6 for the foreign fiscal shocks. 
There are important similarities and differences between Figure 5, which is based on Equation (2), and Figure 3, which relies on Equation (1). The most important difference is that Equation (2) estimates output effects of domestic fiscal shocks that are smaller than those estimated by Equation (1) - which of course is not surprising considering the exclusion of the contemporary government spending term from the right-hand side of Equation (2). The effects from Equation (2) on Figure 5 are smaller than those from Equation (1) on Figure 3 both for the least open subset of economies where the long-run multiplier declines to less than 0.50 and for the most open subset where the long-run effect is estimated to be negative, though not statistically significant. The magnitude of the fiscal multiplier clearly depends on the identification technique chosen.

Note, however, that Figure 5 clearly suggests that the output effects of domestic fiscal shocks are larger for the least open subset than for the most open subset. This is the most important similarity between Figure 5 and Figure 3. It is therefore interesting to observe that while the identification method matters for the size of the multiplier, it does not matter for the finding that the domestic fiscal multiplier is larger in less open economies. This conclusion is independent of the identification technique chosen.

Figure 6 suggests that the spillover effect is larger in the most open subset of economies as implied by Figure 4.

\section{Conclusions}

This paper analyses whether the output effects of domestic and foreign fiscal shocks depend on a country's trade openness. Economic theory predicts that trade openness should reduce the output effects of domestic fiscal shocks (i.e., weaken the domestic multiplier), but increase those of foreign fiscal shocks (i.e., strengthen the spillover effect).

Using annual data from the period of 1970 to 2011, for 179 developed and developing economies, the paper estimated both domestic multipliers and spillover effects, and examined their relationship to trade openness.

The empirical findings show that domestic fiscal shocks are less potent in more open economies, while foreign (rest of the world) fiscal shocks are more potent in more open economies. Put differently, greater trade openness results in a smaller domestic 
multiplier, but in a larger spillover effect.

If the tendency of greater openness continues in the future, our findings suggest that domestic fiscal multipliers should be expected to decline even further, whereas fiscal spillover effects are expected to intensify.

Received 6 November 2013, Revised 11 April 2014, Accepted 9 June 2014 


\section{References}

Auerbach, Alan J. and Yuriy Gorodnichenko. (2012), "Measuring the Output Responses to Fiscal Policy", American Economic Journal: Economic Policy, 4, 1-27.

Auerbach, Alan J. and Yuriy Gorodnichenko. (2013), "Output Spillovers from Fiscal Policy", American Economic Review, 103, 141-146.

Barro, Robert J. and Charles J. Redlick. (2011), "Macroeconomic Effects from Government Purchases and Taxes", Quarterly Journal of Economics, 126, 51-102.

Beetsma, Roel, Massimo Giuliodori, and Franc Klaassen. (2006), "Trade Spill-overs of Fiscal Policy in the European Union: a Panel Analysis", Economic Policy, 21, 640-687.

Bénassy-Quéré, Agnès. (2006), "Short-Term Fiscal Spillovers in a Monetary Union”, CEPII Working Paper No. 2006-12.

Cogan, John F., Tobias Cwik, John B. Taylor, and Volker Wieland. (2010), "New Keynesian versus Old Keynesian Government Spending Multipliers", Journal of Economic Dynamics and Control, 34, 281-295.

Christiano, Lawrence, Martin Eichenbaum, and Sergio Rebelo. (2011), "When Is the Government Spending Multiplier Large?”, Journal of Political Economy, 119, 78-121.

Eggertsson, Gauti B. (2010), “What Fiscal Policy is Effective at Zero Interest Rates?”, in NBER Macroeconomics Annual 2010, Volume 25, 113-124.

Favero, Carlo, Francesco Giavazzi, and Jacopo Perego. (2011), "Country Heterogeneity and the International Evidence on the Effects of Fiscal Policy", NBER Working Paper No. 17272.

Fève, Patrick, Julien Matheron, and Jean-Guillaume Sahuc. (2013), “A Pitfall with Estimated DSGE-Based Government Spending Multipliers", American Economic Journal: Macroeconomics, 5, 141-178.

Fleming, J. Marcus. (1962)“'Domestic Financial Policies under Fixed and under Flexible Exchange Rates", IMF Staff Papers, 9, 369-379.

Frenkel, Jacob A. and Assaf Razin. (1987), “The Mundell-Fleming Model: A Quarter Century Later", NBER Working Paper No. 2321.

Hall, Robert E.(2009), “By How Much Does GDP Rise if the Government Buys More 
Output?”, Brooking Papers on Economic Activity, 183-250.

Ilzetzki, Ethan, Enrique G. Mendoza, and Carlos A. Vegh. (2013), “How big (small?) are fiscal multipliers?", Journal of Monetary Economics, 60, 239-254.

Monacelli, Tommaso, and Roberto Perotti. (2008), “Openness and the Sectoral Effects of Fiscal Policy", Journal of the European Economic Association, Vol.6, 395-403.

Mountford, Andrew and Harald Uhlig. (2009), "What Are the Effects of Fiscal Policy Shocks?", Journal of Applied Econometrics, 24, 960-992.

Mundell, Robert A. (1968), International Economics, Macmillan, New York.

Obstfeld, Maurice. (2001), "International Macroeconomics: Beyond the MundellFleming Model", NBER Working Paper No. 8369.

Ramey, Valerie A. (2011), “Can Government Purchases Stimulate the Economy?”, Journal of Economic Literature, 49, 673-685.

Woodford, Michael. (2011), "Simple Analytics of the Government Expenditure Multiplier", American Economic Journal: Macroeconomics, 3, 1-35.

Wooldridge, J.M. (2010), "Econometric Analysis of Cross-Section and Panel Data", MIT Press, Cambridge, Massachusetts, $2^{\text {nd }}$ edition. 


\section{Appendices}

Table 1. Long-run Domestic Multipliers and Spillover Effects

Full Sample

\begin{tabular}{|c|c|c|c|}
\hline Equation (1) & Ordinary Least Squares & Fixed Effects & Random Effects \\
\hline \multirow{2}{*}{ Domestic multiplier } & $1.21^{* *}$ & $1.14^{* *}$ & $\begin{array}{c}1.18^{* *} \\
\end{array}$ \\
\hline \multirow{2}{*}{ Spillover effect } & $(0.09)$ & $(0.08)$ & $(0.08)$ \\
\hline
\end{tabular}

(Notes) (i) Full Sample includes all 179 economies.

(ii) FE denotes Fixed effects and RE Random Effects.

(iii) Domestic multiplier refers to the domestic output effects of changes in domestic government spending; Spillover effect refers to the domestic output effects of changes in foreign (rest of the world) government spending.

(iv) Standard errors, estimated using the Delta method, are in parentheses. ** and * denote statistical significance at the $1 \%$ and $5 \%$ significance levels, respectively.

Table 2. Long-run Domestic Multipliers and Spillover Effects

A. Least Open Countries

\begin{tabular}{|c|c|c|c|}
\hline Equation (1) & Ordinary Least Squares & Fixed Effects & Random Effects \\
\hline \multirow{2}{*}{ Domestic multiplier } & $1.73^{* *}$ & $1.51^{* *}$ & $1.62^{* *}$ \\
& $(0.28)$ & $(0.24)$ & $(0.26)$ \\
\hline \multirow{2}{*}{ Spillover effect } & 0.97 & 1.06 & 1.01 \\
& $(1.44)$ & $(1.11)$ & $(1.24)$ \\
\hline
\end{tabular}

B. Most Open Countries

\begin{tabular}{|l|c|c|c|}
\hline & Ordinary Least Squares & Fixed Effects & Random Effects \\
\hline \multirow{2}{*}{ Domestic multiplier } & $\begin{array}{c}0.62^{* *} \\
(0.19)\end{array}$ & $\begin{array}{c}0.59^{* *} \\
(0.16)\end{array}$ & $\begin{array}{c}0.61^{* *} \\
(0.17)\end{array}$ \\
\hline \multirow{2}{*}{ Spillover effect } & $\begin{array}{c}4.86^{* *} \\
(1.82)\end{array}$ & $\begin{array}{c}3.93 * * \\
(1.41)\end{array}$ & $\begin{array}{c}4.31^{* *} \\
(1.56)\end{array}$ \\
\hline
\end{tabular}

(Notes) See notes to Table 1. See the text and Appendix B for the Least open and Most open data sets. Estimated standard errors in parentheses. $* *$ and $*$ denote statistical significance at the $1 \%$ and $5 \%$ significance levels, respectively. 
Figure 1. World GDP and World Government Consumption

(US dollars, 2005 prices)

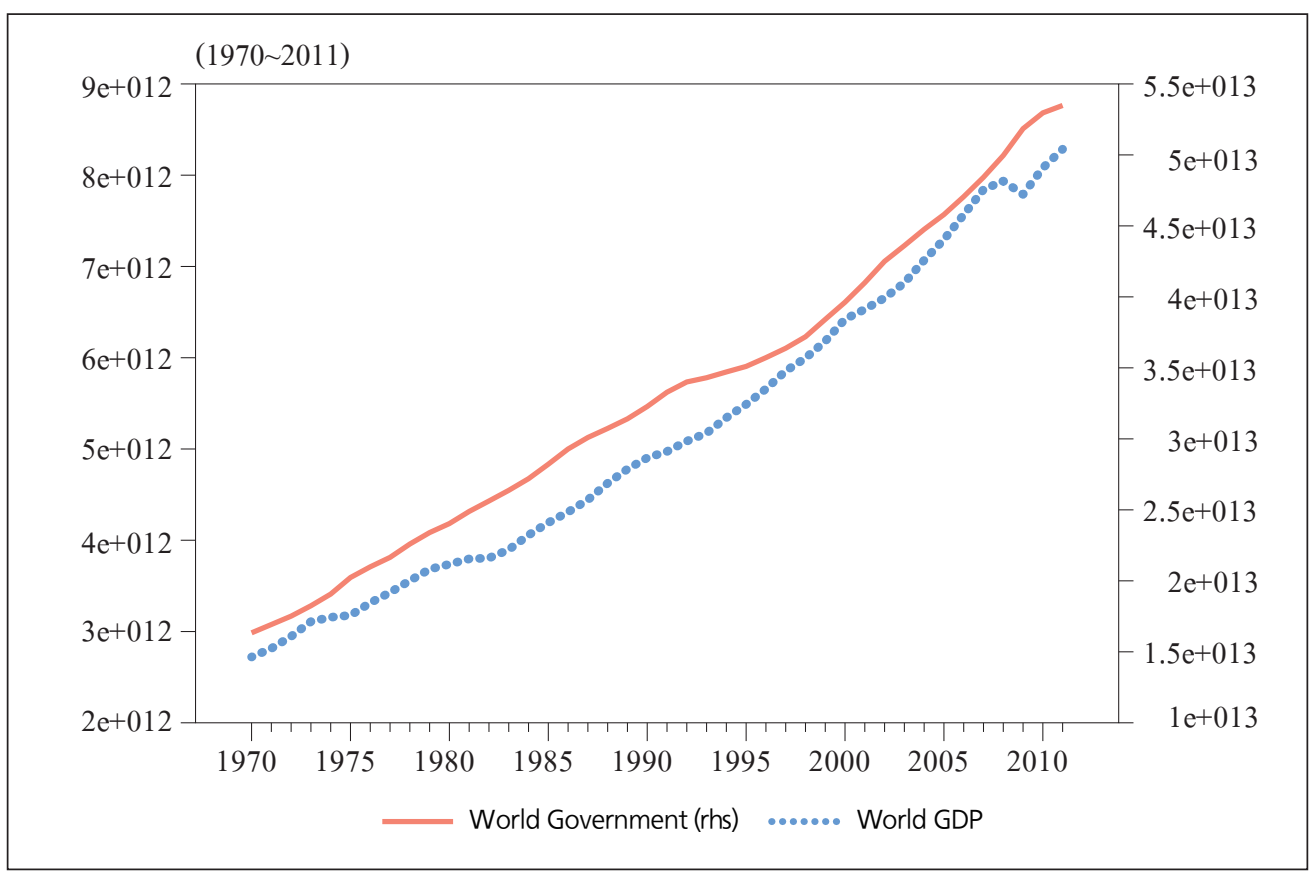

Figure 2. World Government Consumption as a fraction of World GDP

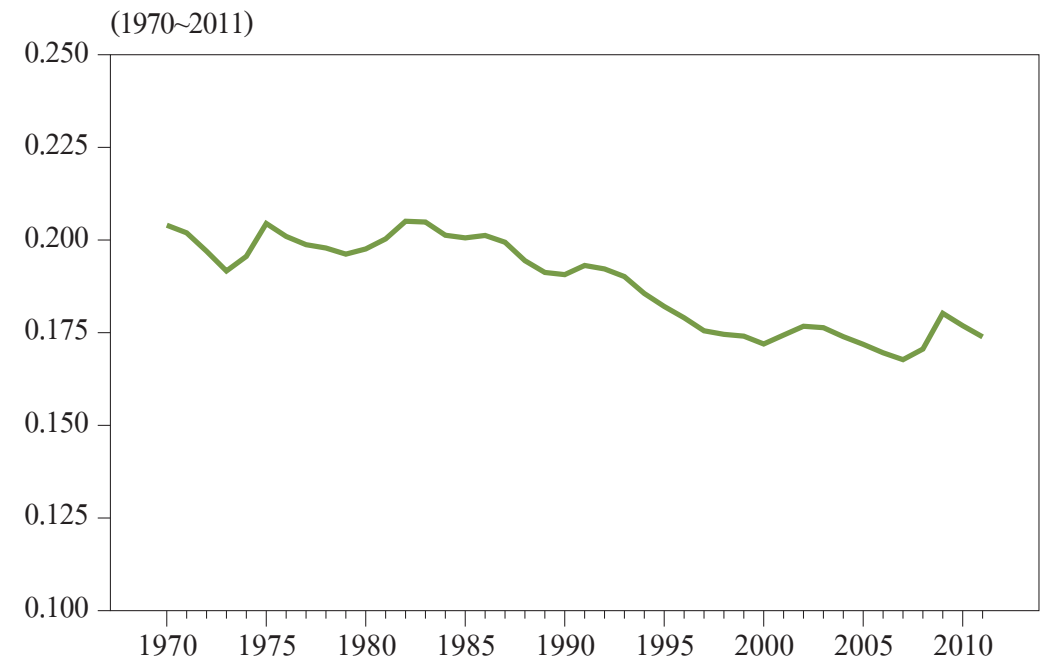


Figure 3. Response of GDP to an increase in Domestic Government Spending

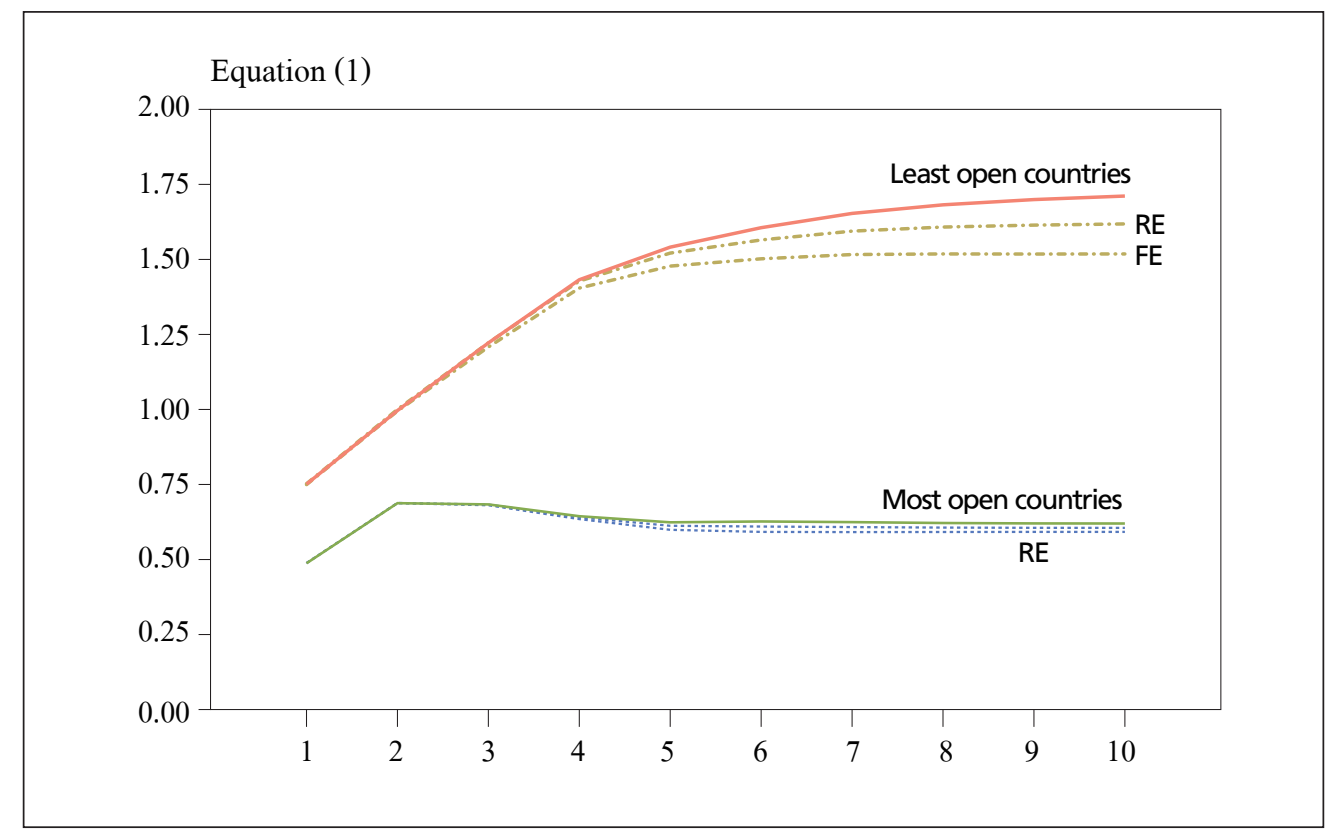

Figure 4. Response of GDP to an increase in Foreign Government Spending

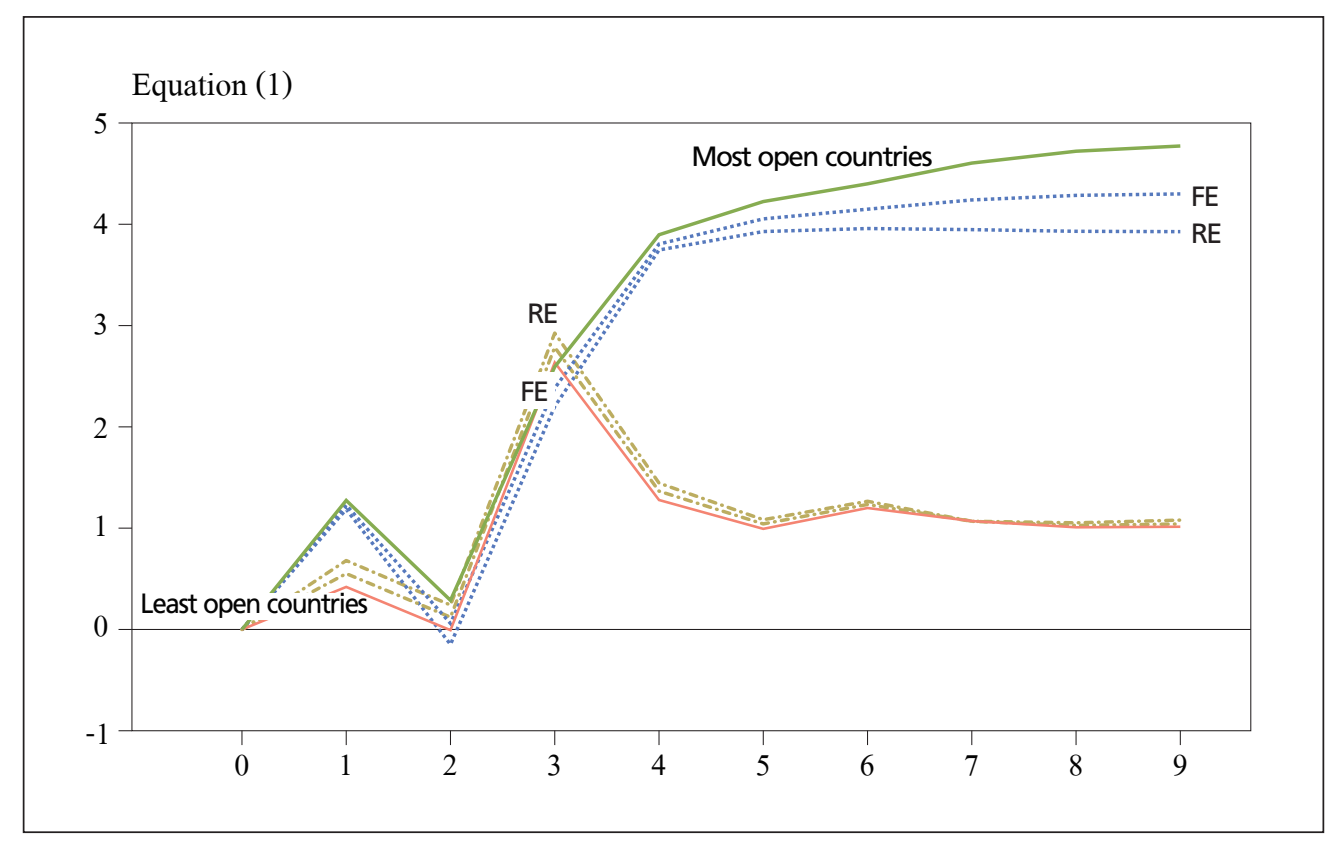


Figure 5. Response of GDP to an increase in Domestic Government Spending

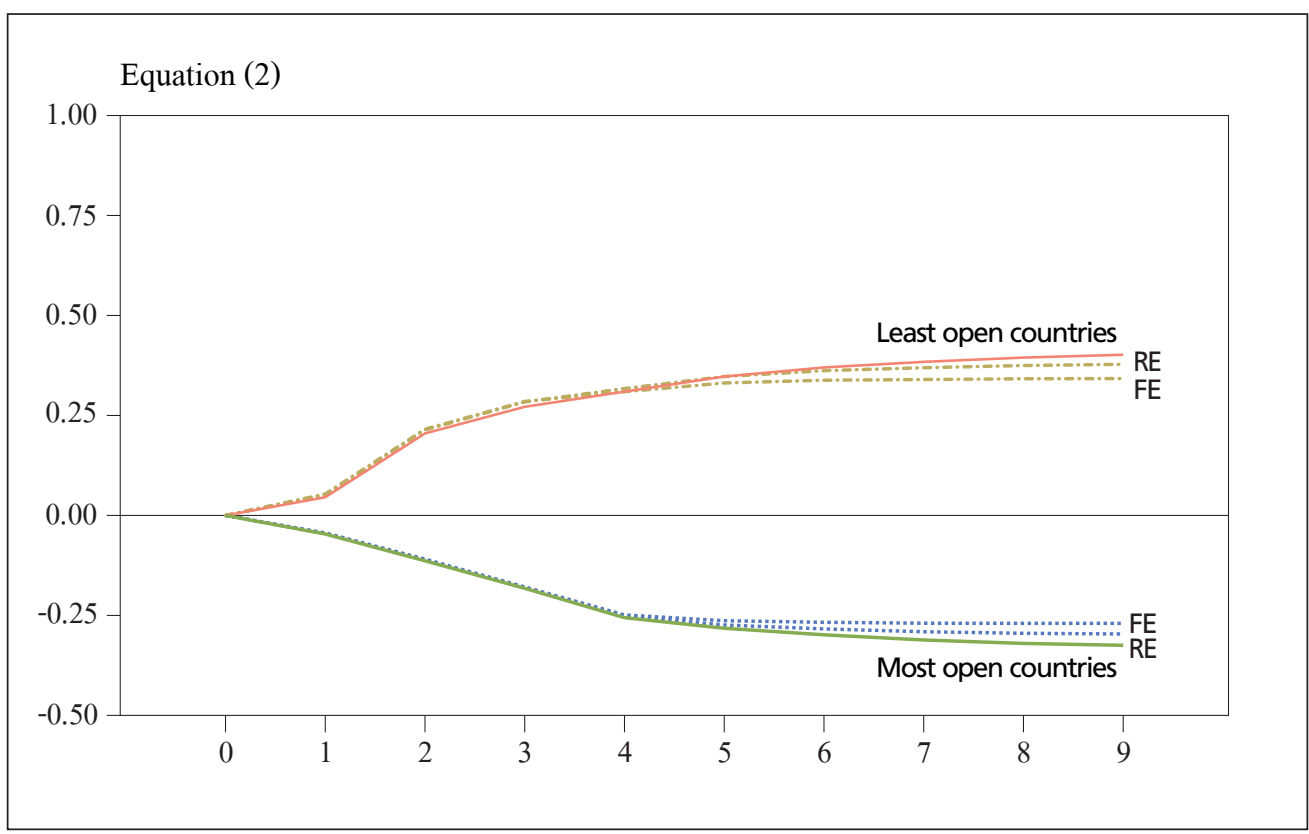

Figure 6. Response of GDP to an increase in Foreign Government Spending

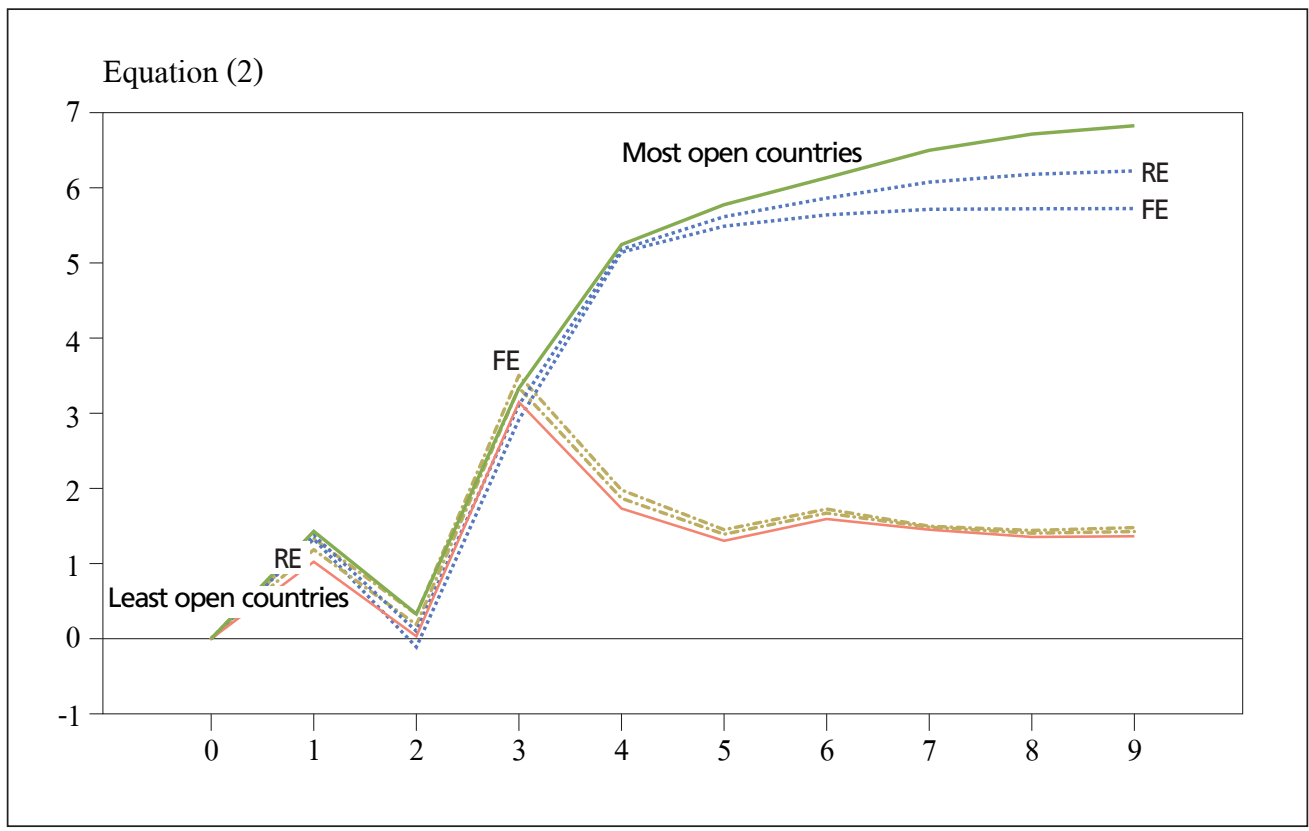




\section{Appendix A}

\section{List of the 179 Economies - Full Sample}

Afghanistan, Albania, Algeria, Andorra, Angola, Anguilla, Antigua and Barbuda, Argentina, Aruba, Australia, Austria, Bahamas, Bahrain, Bangladesh, Barbados, Belgium, Belize, Benin, Bermuda, Bhutan, Bolivia, Botswana, Brazil, British Virgin Islands, Brunei Darussalam, Bulgaria, Burkina Faso, Burundi, Cambodia, Cameroon, Canada, Cape Verde, Cayman Islands, Central African Republic, Chad, Chile, China: People's Republic of, China: Hong Kong SAR, China: Macao SAR, Colombia, Comoros, Congo, Cook Islands, Costa Rica, Côte d'Ivoire, Cuba, Cyprus, Democratic Republic of the Congo, Denmark, Djibouti, Dominica, Dominican Republic, Ecuador, Egypt, El Salvador, Equatorial Guinea, Fiji, Finland, France, French Polynesia, Gabon, Gambia, Germany, Ghana, Greece, Greenland, Grenada, Guatemala, Guinea, GuineaBissau, Guyana, Haiti, Honduras, Hungary, Iceland, India, Indonesia, Iran: Islamic Republic of, Iraq, Ireland, Israel, Italy, Jamaica, Japan, Jordan, Kenya, Kiribati, Kuwait, Lao People's Democratic Republic, Lebanon, Lesotho, Liberia, Libya, Liechtenstein, Luxembourg, Madagascar, Malawi, Malaysia, Maldives, Mali, Malta, Marshall Islands, Mauritania, Mauritius, Mexico, Micronesia (Federated States of), Monaco, Mongolia, Montserrat, Morocco, Mozambique, Myanmar, Namibia, Nauru, Nepal, Netherlands, Netherlands Antilles, New Caledonia, New Zealand, Nicaragua, Niger, Nigeria, Norway, Occupied Palestinian Territory, Oman, Pakistan, Palau, Panama, Papua New Guinea, Paraguay, Peru, Philippines, Poland, Portugal, Puerto Rico, Qatar, Republic of Korea, Romania, Rwanda, Saint Kitts and Nevis, Saint Lucia, Saint Vincent and the Grenadines, Samoa, San Marino, Sao Tome and Principe, Saudi Arabia, Senegal, Seychelles, Sierra Leone, Singapore, Solomon Islands, Somalia, South Africa, Spain, Sri Lanka, Suriname, Swaziland, Sweden, Switzerland, Syrian Arab Republic, Thailand, Togo, Tonga, Trinidad and Tobago, Tunisia, Turkey, Turks and Caicos Islands, Tuvalu, Uganda, United Arab Emirates, United Kingdom of Great Britain and Northern Ireland, United Republic of Tanzania: Mainland, United States, Uruguay, Vanuatu, Venezuela (Bolivarian Republic of), Viet Nam, Zambia, Zimbabwe. 


\section{Appendix B}

Least open and Most open subsets of Economies

\section{Least open subset: 45 economies}

Afghanistan (45.6), Andorra (42.4), Argentina (27.7), Australia (29.4), Bangladesh (28.6), Brazil (17.8), Burkina Faso (44.7), Burundi (27.3), Cameroon (33.3), Central African Republic (40.1), China, People's Republic of (32.3), Colombia (26.6), Cuba (35.7), Democratic Republic of the Congo (40.3), France (36.9), Greece (38.8), GuineaBissau (29.2), Haiti (32.8), India (21.9), Italy (37.9), Japan (19.0), Lao People's Democratic Republic (40.2), Mexico (30.1), Monaco (45.7), Myanmar (0.4), Nepal (36.3), New Zealand (42.8), Pakistan (33.7), Peru (32.7), Poland (40.9), Portugal (45.4), Republic of Korea (45.8), Romania (41.1), Sao Tome and Principe (46.1), Sierra Leone (45.4), Somalia (3.9), South Africa (45.6), Spain (33.9), Turkey (26.4), Uganda (35.5), United Kingdom (40.6), United Republic of Tanzania: Mainland (29.3), United States (17.9), Uruguay (38.1), Zambia (29.1)

\section{Most open subset: 45 economies}

Angola (111.4), Anguilla (110.5), Antigua and Barbuda (139.8), Aruba (173.9), Bahrain (184.4), Belgium (114.8), Belize (115.4), Botswana (112.1), British Virgin Islands (182.1), Cayman Islands (131.6), China: Hong Kong SAR (222.7), China: Macao SAR (148.7), Congo (111.7), Cook Islands (176.0), Djibouti (130.3), Fiji (103.9), Greenland (134.0), Grenada (104.3), Honduras (133.1), Iraq (144.5), Jordan (138.0), Lesotho (148.8), Libya (117.2), Luxembourg (221.8), Malaysia (131.3), Maldives (156.0), Malta (191.3), Marshall Islands (122.5), Mauritius (117.8), Montserrat (111.9), Netherlands Antilles (174.5), Palau (103.1), Panama (167.2), Papua New Guinea (105.3), Puerto Rico (128.4), Saint Kitts and Nevis (103.3), Saint Lucia (140.5), Saint Vincent and the Grenadines (114.4), San Marino (326.7), Singapore (271.0), Solomon Islands (106.0), Swaziland (146.6), Turks and Caicos Islands (124.4), United Arab Emirates (113.7), Vanuatu (105.8) 


\section{Appendix C: Response of GDP to an increase in Domestic and} Foreign government spending

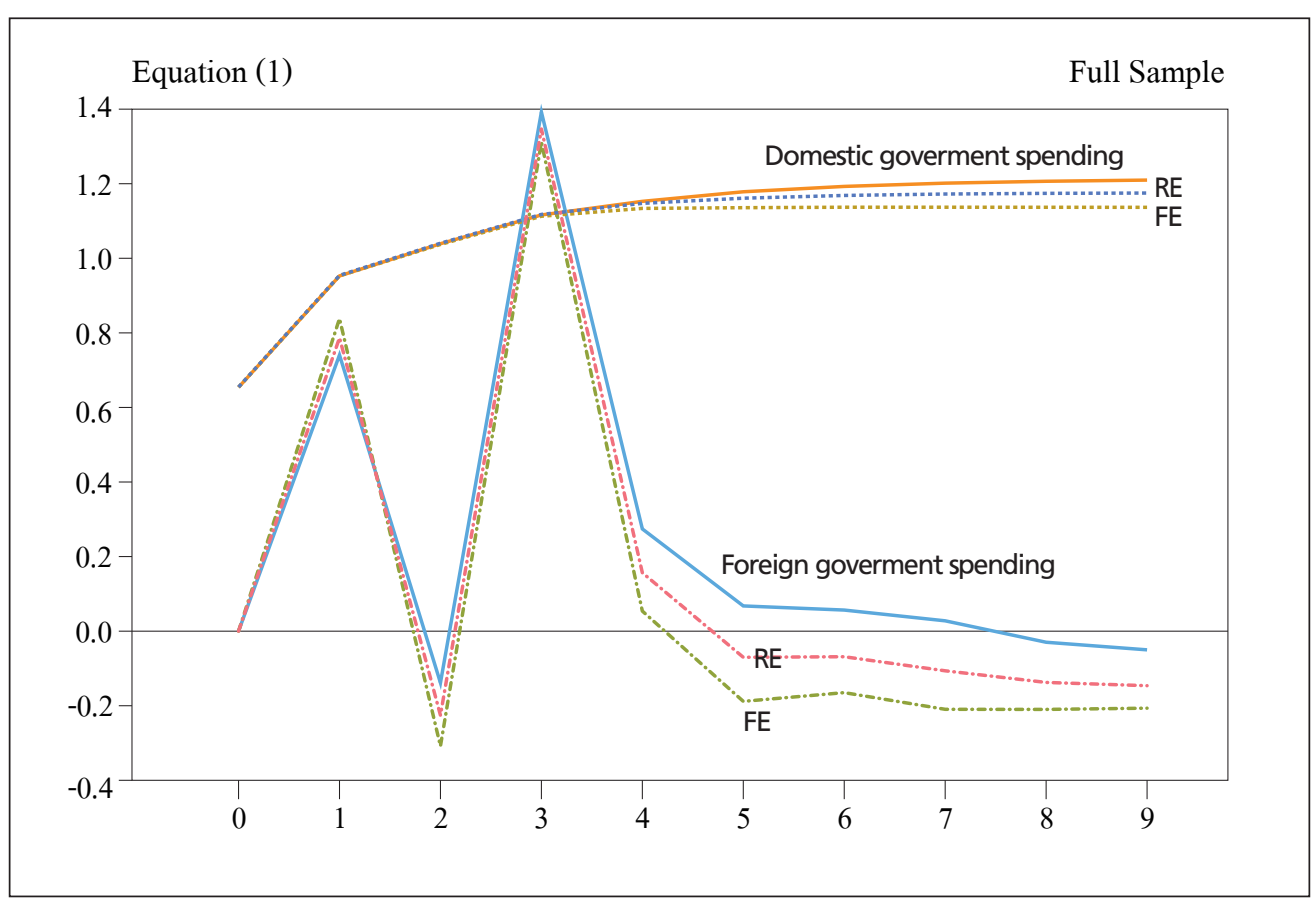

